\title{
Justification of Aggression in Young Reoffenders
}

\author{
Luis Millana* and J. Martin Ramirez
}

Research Group on Sociopsychobiology of Aggression, Universidad Complutense de Madrid, Spain

\begin{abstract}
The degree of acceptance of various forms of aggression in different situations was analyzed by administering self-report questionnaires. Previous studies on justification of interpersonal aggression, in 'normal' adult populations, in quite different cultures, have shown overall similar, but not identical, features. A similar trend of justification, but at a higher level, was expected in special 'deviant' populations, such as prisoners and psychiatric patients. The present study focuses on the way in which young re-offenders serving in reformatories justify different types of interpersonal aggression in a variety of settings. As a control population, a sample of students of similar age living in the same area was used. Results: the young delinquent population justified aggression at a higher level than 'normal' teenagers of similar age in all situations, except 'when communication breaks down'. Specifically their justification of physical aggression as well as of threatening was also higher, whereas no significant differences were found related to passive aggression (hindering) or verbal emotional acts (shouting, being furious, or showing rage). In certain situations a rather striking prevalence among girls was observed. In conclusion, young delinquents showed a higher justification of aggression, notably of its most drastic physical forms, in virtually all situations.
\end{abstract}

Keywords: Re-offenders, delinquency, aggression, reformatory/correctional, socio-moral approval, CAMA.

\section{INTRODUCTION}

How and to what extent a person justifies aggression depends on a wide variety of factors, including prevailing norms in our own culture (Ramirez, 1985a, 1986, 1991, 1993, 2001, 2007). There are good reasons to assume that societies have some moral rules which suggest what forms of aggression become acceptable under particular circumstances.

Several studies conducted by our research group and by other authors comparing the attitudes towards aggression among adults from 'normal' populations in different cultures have been reported in Finland (Lagerspetz \& Wesmman; 1980, Lagerspetz et al., 1988), Britain (Benton, Kumari \& Brain, 1982), Poland (Fraçzek, 1985; Fraçzek, Ramirez \& Torchalska, 1985), Spain (Ramirez, 1985a; 1986; 1991; 1993), Japan and the U.S.A. (Fujihara, 1999; Ramirez \& Fujihara, 1997), Iran (Musazadeh, 1999), India (Ramirez \& Andreu, 2006), Uruguay (Fares et al., 2010, 2011), and China and Cambodia (Lai-Chu et al., in preparation). The scope research should be expanded to investigate some specific subpopulations, defined in terms other than geography or culture, because they may have different codes for the acceptance of aggression. These subpopulations may be characterized as specific professions, such as soldiers or nurses, or what may be known as 'abnormal' or 'deviant' populations like people in prisons or in psychiatric institutions.

Another subpopulation is the different age groups across development. A developmental approach not only clarifies

*Address correspondence to this author at the Research Group on Sociopsychobiology of Aggression, Universidad Complutense de Madrid, Spain; Tel: 34918444 695; Fax: 34913943 069;

E-mail: aggressionresearch@med.ucm.es the role of age in the evolving attitudes towards aggression, such as its justification (Coie, Dodge \& Kupersmidt, 1990), but also addresses youth violence as a serious public health issue that is gaining attention. Data from the Youth Risk Behavior Survey indicated that $44 \%$ of boys and $27 \%$ of girls reported having been involved in a physical fight at least once in the past year, whereas $23 \%$ of boys and $12 \%$ of girls reported having committed at least one previous act of assault (CDC, 2005). These figures are alarming considering the deleterious consequences on the physical and mental health of both victims and perpetrators of youth violence (Cooley-Quile et al., 1995; Fehon et al., 2001; Hancock et al., 2010; Penney et al., 2010).

The conceptual difference between aggression and violence is far from being clear. Some authors present them as two opposing biological concepts, using the dichotomy identified by Erich Fromm: aggression would be an adaptive form of behaviour common to the entire animal kingdom, whereas violence is understood as a malignant biological transformation resulting from mental dysfunction and it is specific to humans (Fromm, 1973). Other authors, in an attempt to present them along a continuum, tend to establish violence as an extreme form of aggression, with eventual legal and criminal implications (Ramirez, 2010). In the present paper, this latter meaning will be used, unless something different is specifically stated; for instance, clearly violent acts, such as killing and torture, are included among the different possible aggressive acts.

In this context, the mutual and close interrelation between violence and the circumstances found within the penitentiary institutions merit some specific consideration too. In prison, there are a number of violence-related factors, such as difficulty to adapt to the environment due to situation exaggeration, aggressive self-assertion, assertive versus sub- 
missive behaviors, interpersonal relationships characterized by dominance or submissiveness, and sexuality disruptions, as well as changes in self-esteem, absence of control over one self's life, permanent anxiety state (in prison, one is always in danger), affectivity disruption, absence of responsibilities, loss of familial and social ties, and verbal communication abnormalities. All above factors have lead to both direct and indirect aggression (Valverde, 1991; Clemente, 1997). In addition, along with the pervasive prison life, the inmates are often forced to 'dedicate' their life to prison, developing a subculture that rules their lives. Life in prison is regulated by unique codes based on a number of principles: power structure, rules, and violence, which result in a characteristic social system ("inmates' code") differing from the formal social prison system. Pressured to adapt to both norms and attitudes, their ruling life in prison, as well as prison subculture, result in disruption of individuals' social and moral roles (Crespo \& Bolaños, 2007). The wish of achieving a social status as high as possible within prison leads to intimidation and bullying, all of which facilitate cognitive distortions, which, in turn, lead to a lack of moral principles (South \& Wood, 2006).

The present research aims to go a step further in this direction: it is a self-report study on justification of aggression in a specific subpopulation -reoffenders or delinquent recidivists - during their teenage years, i.e. when they are still within a clear developmental process. Its comparison with other adolescents attending standard secondary schools may allow us to trace the morality of particular aggressive acts to either universal factors (such as our biology), or to unique cultural factors in specific circumstances (such as having been interned in penal institutions). Understanding the difference causes may lead to effective treatment of the underpinnings of violent crime in the subpopulations. It was expected that redicive offenders might show at least similar or higher justification for most of the violent offenses.

\section{METHODS}

\section{Participants}

Two groups of participants engaged in the present study. One group was recruited from reformatories in the surrounding areas of Madrid: 101 young reoffenders who had committed several kinds of crimes ( 82 males and 19 females) between 12 and 20 years of age (M 17.00, SD 1.31) were selected. This group was matched with a non-inmate control sample consisting of 157 students from a co-educational public school, also in Madrid (91 males and 66 females), between 12 and 20 years of age (M 15.05, SD 1.40). The mean age of the samples, however, was slightly different youth reoffenders were significantly older than youth in the standard setting (17.00 vs. 15.05) and the amount of girls interned was much lower than the girls attending standard schools (see: Table 1).

The kinds of crime these adolescents were interned for in custody centers were qualitatively different (see Appendix A). And, within each category, the intensity and the legal evaluation of the crimes were also different, ranging from misdemeanor crimes to felonies (Wiebush, 1993; Spanish Código Penal y Legislación Complementaria, 2010). But, even if we were aware that some of those peculiarities may have specific influence on norms, reasoning and moral approbation, the present analysis was applied equally to all young re-offenders without distinguishing between the above mentioned different crime categories. Only subjects who were illiterate in the Spanish language, or suffered from a psychiatric disorder, were excluded from the study.

Their participation in the survey was voluntary and they could withdraw at any time without penalty. Ethical clearance was obtained and only those youth who freely agreed to participate completed the self-report. No compensation was received for participating. Youth were informed that their responses to all questionnaires would be kept strictly confidential to the extent provided under the law (i.e. disclosures of intended self or other harm would result in a breach of confidentiality). Furthermore, data collected was used only for research purposes. Researchers remained in the room during survey administration to answer any subjects questions. It lasted 15 minutes approximately.

\section{Questionnaire}

The CAMA (Cuestionario sobre Actitudes Morales sobre Agresión), a version of the original self-report questionnaire elaborated by Lagerspetz and Westman (Lagerspetz \& Wesmman, 1980), subsequently adapted by Ramirez (Ramirez, 1986), was used for measurement. The CAMA questionnaire estimates the participants level of spontaneous aggressiveness, measured as the degree of justification of different types of aggressive acts in various situations in which they may be engaged. A dichotomous format ('Yes' and 'No') was used for all items (See Appendix B). Each positive answer ("yes") to the justification of an act was scored with 1 point, whereas the negative answer ("no") to the justification of an act was scored with 0 points. Each situation therefore could get a global score from 0 (no acceptance at all) to 8 points (maximum of acceptance).

Table 1. Number and Age of Participants

\begin{tabular}{|c|c|c|c|c|}
\hline & \multicolumn{2}{|c|}{$\begin{array}{c}\text { 'Recidivists' } \\
\text { Reformatories } \\
\quad \mathbf{N}=\mathbf{1 0 1}\end{array}$} & \multicolumn{2}{|c|}{$\begin{array}{c}\text { 'Normals' } \\
\text { Secondary School } \\
\quad \mathbf{N}=157\end{array}$} \\
\hline & Males & Females & Males & Females \\
\hline $\mathbf{N}$ & 82 & 19 & 91 & 66 \\
\hline Age range & \multicolumn{2}{|c|}{12 to $20 \mathrm{yrs}$. } & \multicolumn{2}{|c|}{12 to $20 \mathrm{yrs}$. } \\
\hline Mean age (SD) & \multicolumn{2}{|c|}{$17.00 \mathrm{yrs} .(1.31)$} & \multicolumn{2}{|c|}{15.05 yrs. $(1.40)$} \\
\hline
\end{tabular}




\section{Statistical Analysis}

Student's was used for the analysis of the differences between both population groups as well as between both sexes. Mann-Whitney's U for categorical variables $(0=$ no justified, and $1=$ justified), between each act in both population groups was also used. Data statistical analysis was performed by SPSS 17 program.

\section{RESULTS}

An evaluation of the reliability of the psychometric parameters of the instrument showed a satisfactory internal consistency: Cronbach's Alpha from 0.77 to 0.91. Its previous validation in different cultural backgrounds had also found similar values: 0.91 for Finish samples (Lagerspetz \& Wesmman; 1980), 0.88 for Iranian samples (Musazadeh, 1999), between 0.71 and 0.83 for several acts in an Uruguayan sample (Fares et al., 2010), and 0.87 in Carmines theta, similar to Cronbach's Alpha, for a Spanish sample (Andreu, Ramirez \& Raine, 2006).

A factorial analysis of the main components of CAMA and varimax rotation distinguished two groups of situations relatively independent $(>0.35)$, which lead to what may be called instrumental factor (defense of oneself, of others, and of property) and emotional factor (anger, punishment, no communication).

Justification of aggression was higher in young reoffenders than in 'normal' teenagers of similar age for most acts, but not for the extreme ones (killing, on one side, and passive aggression, as being ironic and hindering, on the another one) (see Table $\mathbf{2}$ and Figs. (1a to 1f)).

The young re-offenders showed a higher justification of aggression than 'normal' teenagers of similar age did in all situations, except 'when communication breaks down' and 'to obtain sexual objectives' (see Table 3 and Fig. (2)).

Table 2. Justifications of Different Aggressive Acts: Reformatories vs. Secondary School

\begin{tabular}{|c|c|c|c|c|c|c|c|c|}
\hline & $\begin{array}{l}\text { Being } \\
\text { Ironical }\end{array}$ & Threatening & $\begin{array}{c}\text { Stopping } \\
\text { Somebody from } \\
\text { Doing Something }\end{array}$ & $\begin{array}{l}\text { Using } \\
\text { Torture }\end{array}$ & $\begin{array}{c}\text { Shouting } \\
\text { Angrily }\end{array}$ & Hitting & $\begin{array}{l}\text { Getting } \\
\text { Furious }\end{array}$ & Killing \\
\hline & $\mathbf{P}$ & $\mathbf{P}$ & $\mathbf{P}$ & $\mathbf{P}$ & $\mathbf{P}$ & $\mathbf{P}$ & $\mathbf{P}$ & $\mathbf{P}$ \\
\hline In self-defense & .368 & $.009 * *$ & .089 & $.007 * *$ & .419 & $.001 * *$ & .367 & .555 \\
\hline To protect another person & .745 & $.000 * *$ & .497 & $.020^{*}$ & .410 & $.002 * *$ & .232 & $.045^{*}$ \\
\hline $\begin{array}{l}\text { When communication breaks } \\
\text { down }\end{array}$ & .878 & .097 & .103 & .780 & .253 & $.011^{*}$ & $.035^{*}$ & .072 \\
\hline When angry & .102 & $.000 * *$ & .134 & .196 & .209 & $.000 * *$ & .705 & .918 \\
\hline To protect one's property & .855 & $.000 * *$ & .214 & $.013^{*}$ & .053 & $.000 * *$ & $.014^{*}$ & .116 \\
\hline As punishment & .308 & $.006^{* *}$ & .622 & $.033^{*}$ & .356 & $.000 * *$ & .800 & .084 \\
\hline To obtain sexual objectives & .205 & .462 & .582 & .505 & .637 & .935 & .817 & .163 \\
\hline To preserve onself's reputation & .760 & $.000 * *$ & .269 & .138 & $.032 *$ & $.000 * *$ & .166 & .860 \\
\hline
\end{tabular}

* Significant difference at 0.05 .

** Significant difference at 0.01 .

Table 3. Different Situations: Justification in Reformatories vs. Secondary School

\begin{tabular}{|c|c|c|c|}
\hline Situations & Student's t & p & a \\
\hline \hline Self-defense & 2.03 & .043 & .05 \\
\hline To Protect others & 3.29 & .001 & .01 \\
\hline When communication fails & 1.78 & .076 & .001 \\
\hline When angry & 2.8 & .000 & .01 \\
\hline To protect oneself's property & 4.61 & .022 & .05 \\
\hline As punishment & 2.31 & .092 & $\mathrm{~ns}^{+}$ \\
\hline To obtain sexual objectives & -0.09 & .003 & .01 \\
\hline
\end{tabular}

$+n s$ : not significant. 


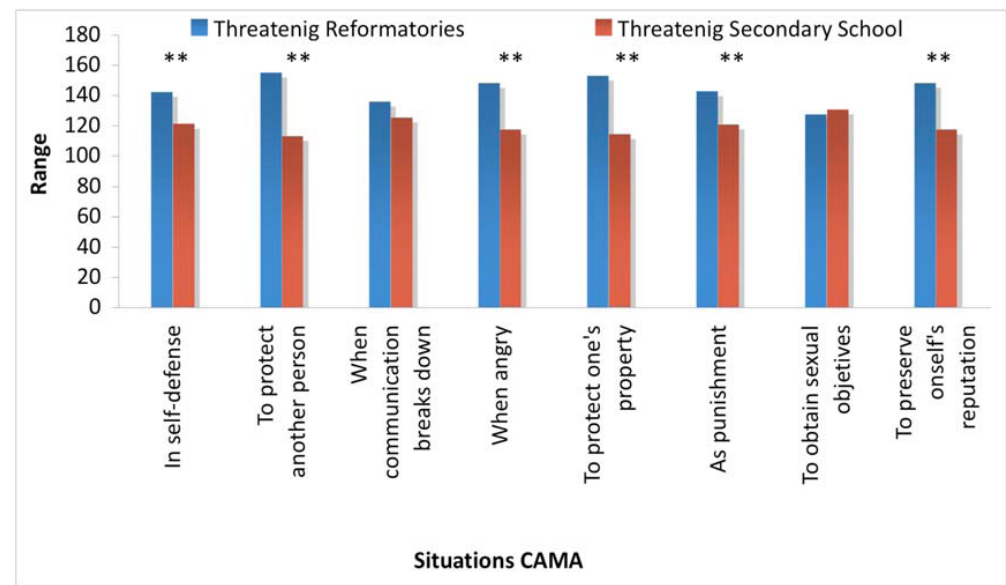

Fig. (1a). "Threatening" Justification in reformatories $v s$. secondary school.

The punctuation of each act is within a range from 113.05 to 155.07.

$*$ Significant difference at $0.05, * *$ Significant difference at 0.01 .

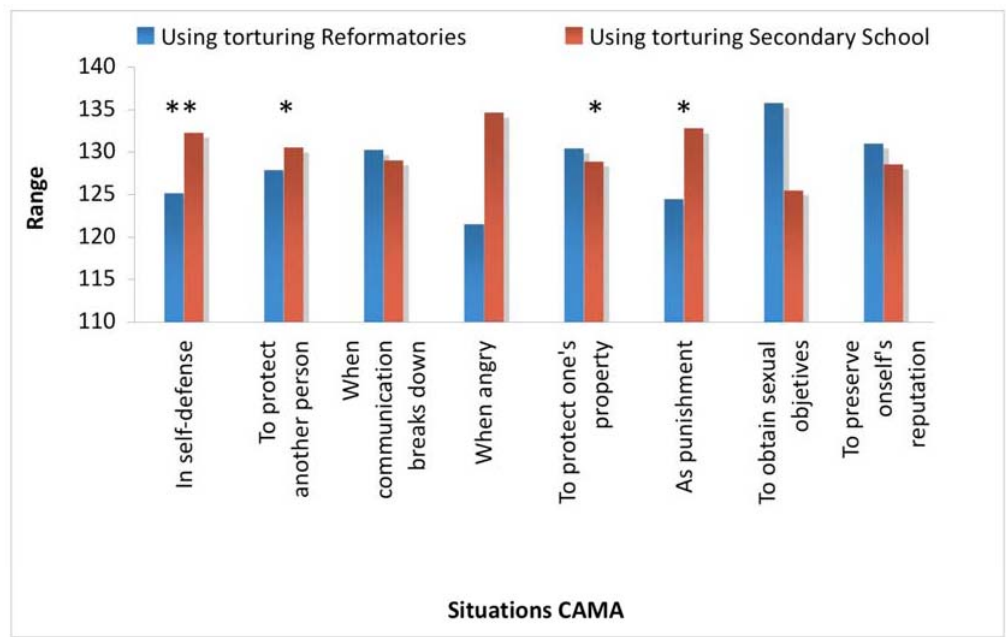

Fig. (1b). "Torturing" Justification in Reformatories vs. Secondary school.

The punctuation of each act is within a range from 121.52 to 135.75 .

$*$ Significant difference at $0.05, * *$ Significant difference at 0.01 .

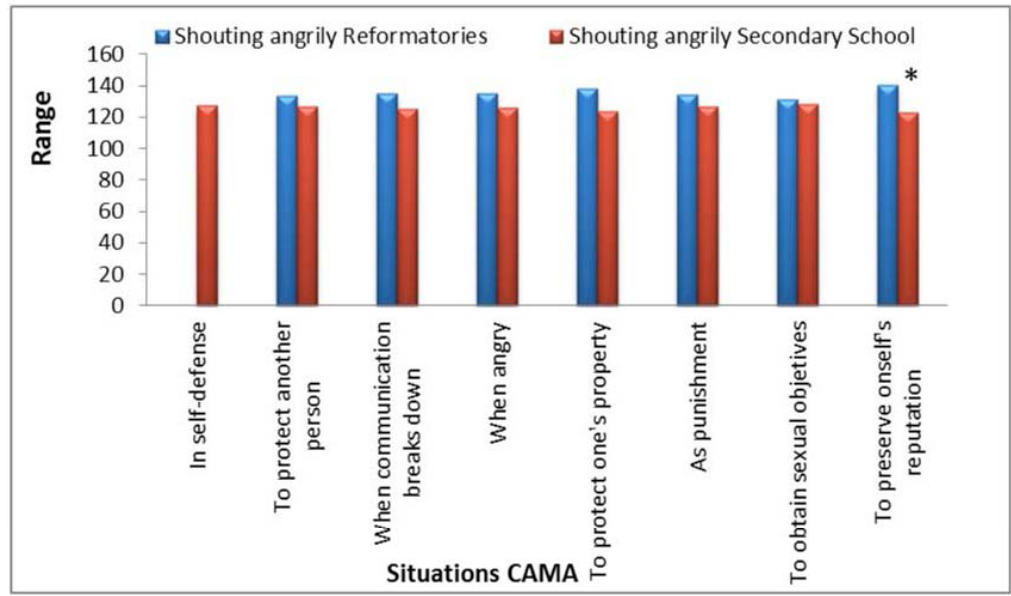

Fig. (1c). "Shouting Angrily" Justification in Reformatories vs. Secondary school.

The punctuation of each act is within a range from 122.59 to 140.25 .

*Significant difference at $0.05, * *$ Significant difference at 0.01 . 


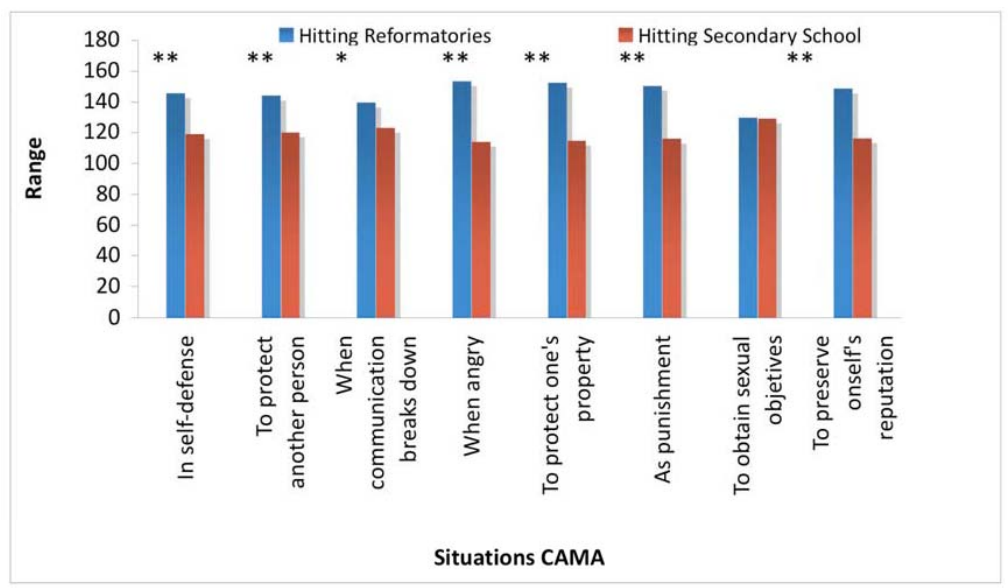

Fig. (1d). "Hitting" Justification in Reformatories vs. Secondary school.

The punctuation of each act is within a range from 114.04 to 153.52 .

*Significant difference at $0.05, * *$ Significant difference at 0.01 .

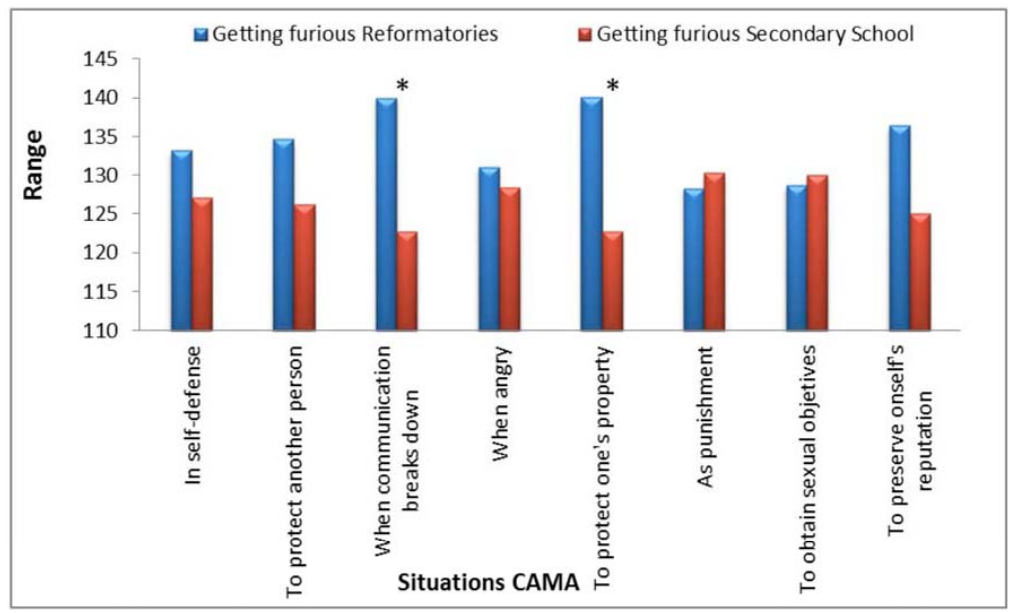

Fig. (1e). "Getting Furious" Justification in Reformatories vs. Secondary school.

The punctuation of each act is within a range from 122.7 to 140.06 .

*Significant difference at $0.05, * *$ Significant difference at 0.01 .

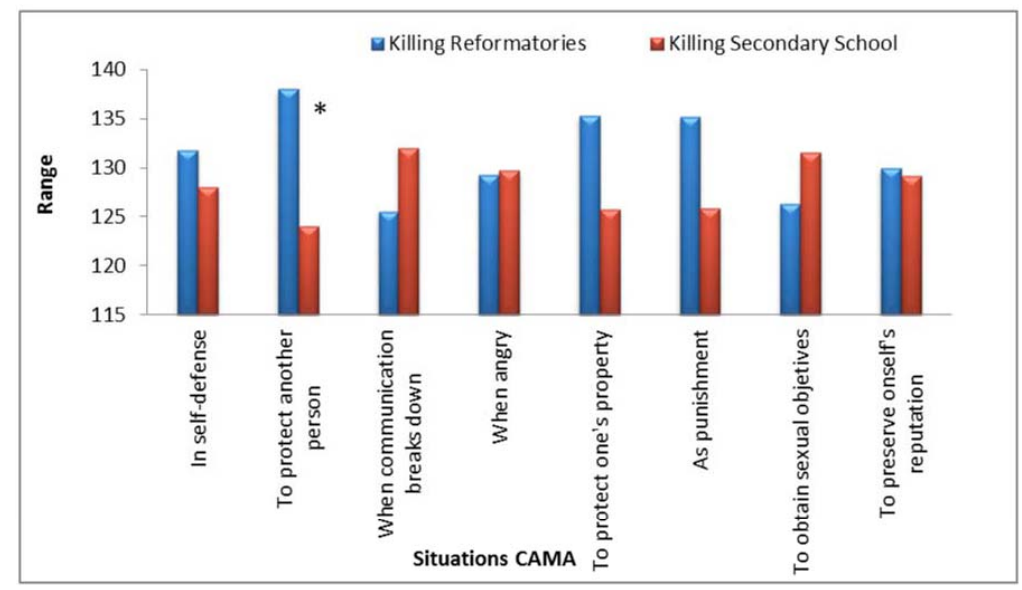

Fig. (1f). "Killing" Justification in Reformatories vs. Secondary school.

The punctuation of each act is within a range from 123.97 to 138.09 .

*Significant difference at $0.05, * *$ Significant difference at 0.01 . 


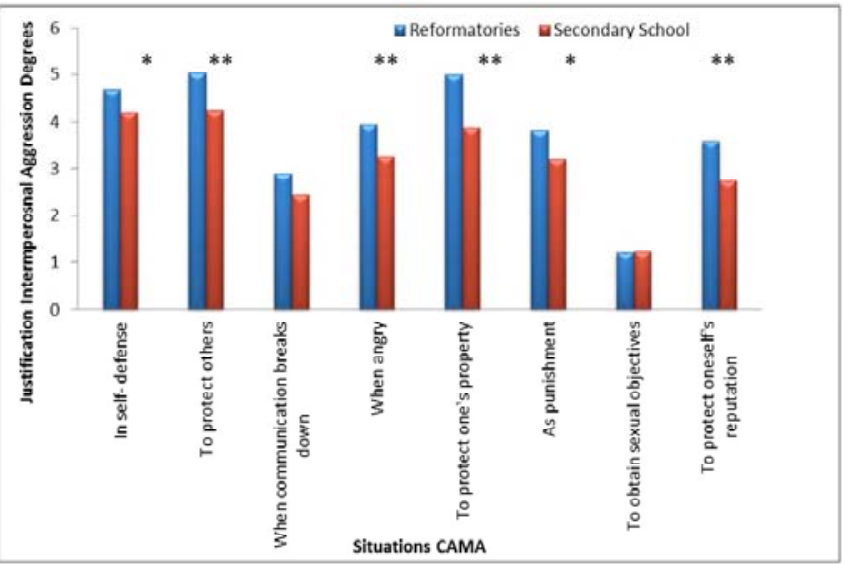

Fig. (2). Different Situations: Justification in Reformatories vs. Secondary school.

The punctuation of each act is within a range from 0 to 8 .

*Significant difference at 0.05 .

**Significant difference at 0.01 .

The level of justification of aggression was higher in young re-offender girls than in young re-offender boys in all situations, even if this difference was significant only in selfdefense (see Table 4 and Fig. (3)).

The young re-offender girls also showed a significantly higher level of justification of aggression than the girls in the control group in all situations, except for obtaining sexual objectives (see Table 5 and Fig. (4)). The young re-offender boys showed a significantly higher level of justification of aggression than the control counterparts only for 'defense of property' and 'defense of others' as well as 'because of anger', but not for the rest of justifications (see Table $\mathbf{6}$ and Fig. (5)).

\section{DISCUSSION}

The previous reports in 'normal' adult populations have shown a high consistency in the level of approval of interpersonal aggression. For instance, certain drastic acts were never justified, and serious aggression was always less

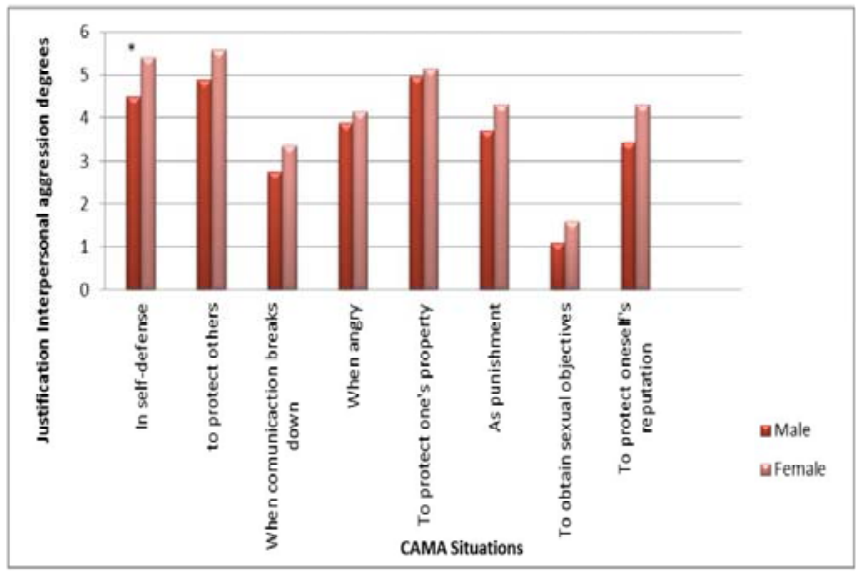

Fig. (3). Sex Differences: Justification in Re-offenders. The punctuation of each act is within a range from 0 to 8 . *Significant difference at 0.05 .

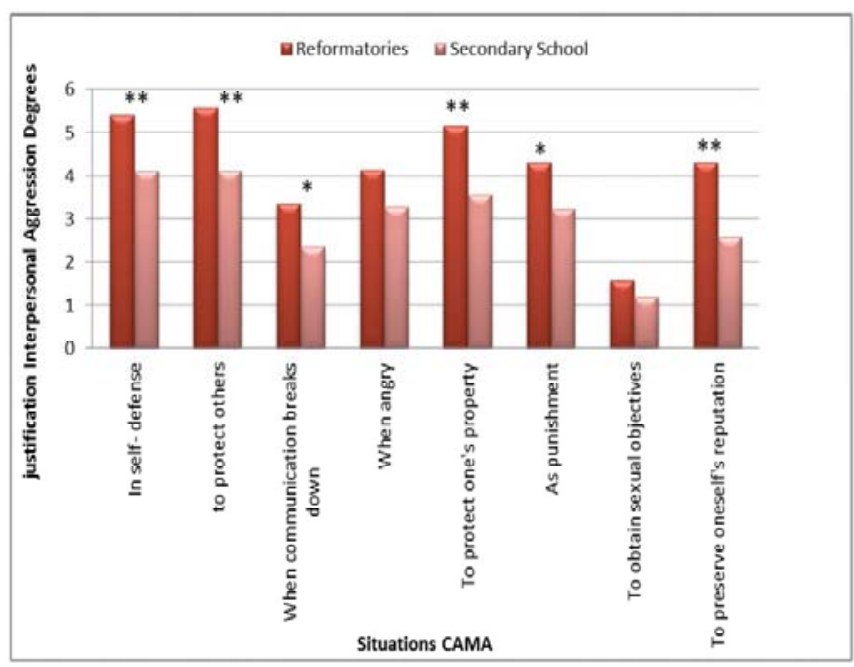

Fig. (4). Sex Differences Among Females: Justification in Reformatories vs. Secondary school.

The punctuation of each act is within a range from 0 to 8 .

*Significant difference at 0.05 .

** Significant difference at 0.01 .

Table 4. Sex Differences: Justification in Re-Offenders

\begin{tabular}{|c|c|c|c|}
\hline Situation & Student's t & $\mathbf{\alpha}$ & .05 \\
\hline \hline Self-defense & -2.18 & .20 & $\mathrm{~ns}$ \\
\hline To Protect others & -1.26 & .25 & $\mathrm{~ns}$ \\
\hline When communication breaks down & -1.15 & .60 & $\mathrm{~ns}$ \\
\hline When angry & -0.51 & .69 & $\mathrm{~ns}$ \\
\hline To protect oneself's property & -0.39 & .31 & $\mathrm{~ns}$ \\
\hline As punishment & -1.01 & .24 & $\mathrm{~ns}$ \\
\hline To obtain sexual objectives & -1.17 & .40 & $\mathrm{~ns}$ \\
\hline
\end{tabular}




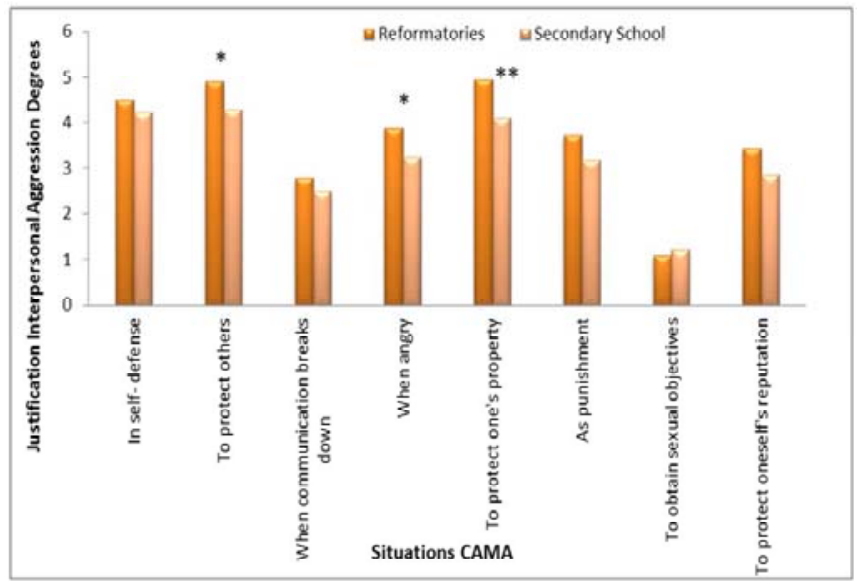

Fig. (5). Sex Differences among Males: Justification in Reformatories vs. Secondary school.

The punctuation of each act is within a range from 0 to 8 .

*Significant difference at 0.05 .

$* *$ Significant difference at 0.01 .

accepted than mild aggression (Wann et al., 2003). Hasking et al., (2011) have also found that by far the most prevalent forms of delinquent behavior endorsed by adolescents aged 12-17 (mean: 14 yrs.) were the least offensive from a crimi- nal behavior standpoint (drinking underage, viewing pornography, littering, making obscene phone calls, and lying). These findings support the hypothesis that morality may have some biological roots, reflected in the existence of some basic rules of 'common sense' in human beings. For instance, in aggression there is a rather universal higher justification of milder acts or of those ones elicited by provocation. Even more, there is evidence suggesting that selfregulatory abilities such as empathy, self-awareness, altruism, cooperation, fairness or prosocial behavior may also be found in other animal species. Therefore, morality, far from being something unique to humans, could have also evolved in a continuous with other animals (Ramirez, 2007; De Waal, 2011).

This, however, does not preclude the influence of specific social circumstances on judgments about aggression. Prevailing cultural norms and role expectations in any specific society influence what is judged to be their code about acceptance or justification of different forms of aggression in certain circumstances. In our case, as it was expected, the violent behavioral actions that are deemed counter-normative and socially unacceptable in a standard society showed a higher level of acceptance in the subculture that rules the life in reformatory centers than in standard secondary schools. This may be explained by Bandura's social learning theory

Table 5. Sex Differences Among Females: Justification in Reformatories vs. Secondary School

\begin{tabular}{|c|c|c|c|}
\hline Situations & t of Student & p & .002 \\
\hline \hline Self-defense & 3.25 & .004 & .01 \\
\hline To Protect others & 2.92 & .038 & .01 \\
\hline When communication breaks down & 2.11 & .056 & $\mathrm{~ns}{ }^{+}$ \\
\hline When angry & 1.94 & .001 & .01 \\
\hline To protect oneself's property & 3.42 & .042 & .05 \\
\hline As punishment & 2.06 & .4 & $\mathrm{~ns}$ \\
\hline To obtain sexual objectives & 0.83 & .002 & .01 \\
\hline
\end{tabular}

+ ns: no significant.

Table 6. Sex Differences among Males: Justification in Reformatories vs. Secondary School

\begin{tabular}{|c|c|c|c|}
\hline Situations & t de Student & p & a \\
\hline \hline Self-defense & 0.92 & .35 & $\mathrm{~ns}$ \\
\hline To Protect others & 2.09 & .038 & .05 \\
\hline When communication breaks down & 0.93 & .35 & .05 \\
\hline When angry & 2.13 & .034 & .01 \\
\hline To protect oneself's property & 2.89 & .087 & $\mathrm{~ns}^{+}$ \\
\hline To punishment & 1.72 & .67 & $\mathrm{~ns}^{+}$ \\
\hline To obtain sexual objectives & -0.42 & .10 & $\mathrm{~ns}^{+}$ \\
\hline To preserve onself's reputation & 1.63 & & .004 \\
\hline
\end{tabular}


(Bandura, 1971; 1986; 1987). According to this theory, violent acts would be more frequent and intense in a favorable environment than when there is a social disapproval. Although there are cases of violence that clearly cannot be tolerated in any civilized society, such as murder and torture, other behaviors may be labeled as dangerous or socially unacceptable merely because they are offensive to group sensibilities or because they challenge or upset an immoral or unjust status quo. Judgments of aggressiveness reflect the values and interests of those doing the judging. This may explain why a higher permissive atmosphere among delinquents, like the one analyzed in the present study with young recidive delinquents, may lead to a facilitation of violence and, consequently, of its higher acceptance, or even its exacerbation trying 'to take the law by one's own hand' once they return to live within the standard society. This may explain the higher level of justification seen among youth delinquents in cases of personal attack, such as self-defense and defense of others or of property, as shown in the present research.

Also, people prevented from reaching a desired goal may become aggressive when the interference is thought illegitimate or arbitrary. Even justified, reasonable, and legitimate frustrations for which excusable reasons exist can activate the instigation to aggression (Dollar et al., 1939; Berkowitz, 1989a).

There are some possible variables mediating the causal underpinnings of youth delinquency: a lack of stable social links, a lack of affect or cognition, or even, inadequate internal moral feelings (Ramirez, 1985b; Wiebush, 1993). De Mey found a medium-low level of moral judgment in young delinquents when comparing them with two control groups of non-delinquents (Tavecchio et al., 1999). This may also be linked to an eventual higher impulsivity or slower psychobiological development of maturity timing in this kind of adolescents.

According to the general theory of crime (Gottfrenson \& Hirschi, 1990), a 'common cause' leading to a wide range of delinquent behaviors stemming from poor self-control (Brownfiekd \& Sorenson, 1993), typically conceptualizes adolescent delinquency as a single one-dimensional construct. Following this approach, delinquent youth would be more likely to be 'generalists' in their offending practices than 'specialists': deviance may represent a broad aggregation of behaviors (Thompson et al., 1996). Recent evidence (Hasking, Scheier \& Abadía, 2011), however, suggests that delinquency may be better viewed typologically as consisting of several classes of qualitatively distinct behaviors, which can be used to categorize youth.

Based on the assumption that developmental changes in processing information about aggression leads to a decline of its use, a similar tendency towards a higher level of violence justification in adolescents compared with adults would also be expected. As children grow older and mature aggression is evaluated more negatively and its justification becomes lower. In a lack of consistency with what one would expect based on the above mentioned rationale, however, a previous comparison between young and adolescent students (Millana, Halty \& Ramirez, 2009) showed very few age differ- ences; these being a significantly higher justification of aggression in older students (university) than among younger ones (high school), for instance for protecting others. Our present results with young re-offenders supported these previous findings with 'standard' students of different ages, showing a higher level of violence justification among young delinquents than among the control group, two years of age younger. Though it may also be explained by our hypothesis in favor of a propensity towards a higher justification of violence within a delinquent subculture. It is possible that both eventual explanations may converge.

The question would be at which age does the cognitive maturation expected in adults start. Literature shows a curvilinear level of aggression in adolescence, descending only at the end of it. For instance, a peak was found at the age of fourteen in the use of physical aggression (Loeber, 1982; Linderman, Harakka \& Keltikangas-Järvinen, 1997; Osterman et al., 1998), and at age 11 in indirect aggression (e.g., Lagerspetz, 1988; Osterman et al., 1998; Björkqvist, Lagerspetz \& Kaukiainen, 1992). Though earlier or later, this timing arrives with the onset of the adulthood, in close relationship with some biological and social factors related to it, such as hormonal changes, appearance of sexual relations, starting to work, moving from the parental home towards a more independent environment, etc. (Dorn, Susman \& Ponirakis, 2003). In order to obtain a deeper understanding of the topic, further studies should also focus on adult delinquents, comparing them to their younger counterparts who have not been under the justice system.

Another limitation of the present study that warrants caution in the interpretation of findings is that the analyses were conducted using a relatively small sample, including a perhaps insufficient number of female reoffenders. This unbalance between both sexes is to be the case not only among adult penal population, but also in the case of young reoffenders: there are many more males than females in penal reformatories. This fact refrains us from deepening into the discussion of the finding that in certain situations there is a higher level of justification of aggression among young reoffender girls in comparison with boys interned in custody centers This is rather striking given the practically unanimous acceptance that physical aggression is higher among males, not only because of psychobiological reasons, but also due to cultural differences in behavioral expectations of both sexes: a rough behavior that may be socially unacceptable in girls, may be accepted, and even praised, in boys (Ramirez, 2001). Studies that have examined sex differences in this manner generally report that the same variables predict violence and delinquency for both males and females (e.g. experiencing or witnessing violence (Blum, Ireland \& Blum, 2003), antisocial peers and attitudes (Simourd \& Andrews, 1994). Although the broader literature thus suggests greater sex similarities than differences in the developmental course (e.g. (Fontaine et al., 2008), a replication with a larger sample is, therefore, warranted.

Finally, the utilization of self-reports has often been criticized because they are likely to be influenced by social desirability; i.e. actual behavior needs not to conform to ideal models of conduct (Cohen, 1955). Subjects may give only desirable answers to the hypothetical situations described to 
them (Berkowitz, 1989b). It must be clarified however that our research did not focus on absolute levels of aggression, but only on the relationship between the different samples. Despite this fact, data from self-report studies are also informative since many acts of violence are not detected by official statistics. Also, high self-awareness magnifies the correlates between self-reports and behavior (Scheier \& Fenigstein, 1974; Turner \& Layton, 1975). A meta-analysis done by Bettencourt et al., (Bettencourt et al., 2006) has found a positive correlation between aggression, as measured by self-reports, and personality dimensions. This suggests the usefulness of self-report instruments for early identification of individuals with a personality prone to aggression and, consequently, in facilitating appropriate treatment (Stanford, Greve \& Dickens, 1995).

Taken together, our findings emphasize a higher justification of aggression among young re-offenders, with a rather striking prevalence among girls in certain situations. Future research based on clinical and forensic samples should provide further insight in how criminal individuals conceptualize aggression and violence and how eventually it evolves along their psychobiological development. Undoubtedly, such improved knowledge would be of interest for individuals and for society as a whole to understand the causal underpinnings of violent crime and, more specifically, for an effective prevention, early intervention, correctional rehabilitation and treatment, and judicial initiatives in the front of violent crime.

\section{CONFLICTS OF INTEREST}

None declared.

\section{ACKNOWLEDGEMENTS}

The authors acknowledge the invaluable assistance of Irene González Reyes, Eva Expósito, Violet Cheung, Juan Manuel Arias Martín and Agency for Reeducation and Reintegration into Society of the Abused Minor (ARRMI) in different matters.

\section{APPENDIX A: TOPOLOGY OF CRIMES COMMITTED BY THE ADOLESCENT OFFENDERS IN THE PRESENT STUDY}

1) Offences against property

2) Drug law violations (drug abuse and drug trafficking)

3) Offences against road safety

4) Injury

5) Crimes against persons: robbery, homicide, murder

6) Offences against sexual freedom (rape, assault)

7) Offences related to elective termination of pregnancy

8) Fraud/forgery

9) Offences against personal freedom

10) Offences against public order (disordered conduct, violation of safety school ordinance, weapons offenses, obstruction of justice)

11) Others

\section{APPENDIX B: CAMA}

\begin{tabular}{|l|l|}
\hline \multicolumn{2}{|c|}{$\begin{array}{c}\text { (Questionnaire on Moral Attitudes Toward Aggression) } \\
\text { ○ J. Martin Ramirez (1985) }\end{array}$} \\
\hline \hline List of Situations & $\begin{array}{l}\text { List of Aggressive Acts } \\
\text { 1. In self-defense }\end{array}$ \\
2. To protect another person & 2. Threatening \\
3. When communication breaks & 3. Stopping somebody from...doing \\
down & something \\
4. When angry & 4. Using torture \\
5. To protect one's property & 5. Shouting angrily \\
6. As punishment & 6. Hitting \\
7. To obtain sexual objectives & 7. Getting furious \\
8. To preserve self's reputation & 8. Killing \\
\hline
\end{tabular}

\section{REFERENCES}

Andreu, J. M.; Martín Ramirez, J.; Raine, A. (2006). Un modelo dicotómico de la agresión: valoración mediante dos auto-informes (CAMA y RPQ). Psicopatología Clínica, Legal y Forense, 5, 25-42.

Bandura, A. (Ed.) (1971). Psychological modeling: Conflicting theories. Chicago: Aldine-Atherton.

Bandura, A. (1986). Social foundations of thought and action: A social cognitive theory. Englewood Cliffs, NJ: Prentice Hall.

Bandura, A. (1987). Teoría del aprendizaje social. Madrid: Espasa-Calpe.

Benton, D.; Kumari, N.; Brain, P. F. (1982). Mild hypoglycaemia and questionnaire measures of aggression. Biological Psychology, 14, 129135 .

Berkowitz, L. (1989b). Advances in experimental social psychology, 22, Orlando, Florida: Academic Press.

Berkowitz, L. (1989a). Frustration-aggression hypothesis: examination and reformulation. Psychologycal Bulletin, 106, 59-73.

Bettencourt, B.A.; Talley, A.; Benjamin, A.J.; Valentine, J. (2006). Personality and aggressive behavior under provoking and neutral conditions: a meta-analytic review. Psychological Bulletin 132, 751777.

Björkqvist, K.; Lagerspetz, K.M.J.; Kaukiainen, A. (1992). Do girls manipulate and boys fight? Developmental trends in regard to direct and indirect aggression. Aggressive Behaviour 18, 117-127.

Blum, J.; Ireland, M.; Blum, R. W. (2003). Gender differences in juvenile violence: A report from add health. Journal of Adolescent Health, 32, 234-240.

Brownfield, D.; Sorenson, A.M. (1993). Self-control and juvenile delinquency. Theoretical issues and an empirical assessment of selected elements of a general theory of crime. Deviant Behavior 14, 243-264.

Centers for disease control and prevention (2005). Measuring violencerelated attitudes, behaviors, and influences among youths: A compendium of assessment tools, Atlanta.

Clemente, M. (1997). Los efectos psicológicos y psicosociales del Clemente encarcelamiento. In M. y J. Núñez (Coord.) Psicología Jurídica Penitenciaria II. Madrid: Fundación Universidad-Empresa, (pp 385407).

Cohen, Albert K. (1955). Delinquent Boys: The Culture of The Gang. The Free Press.

Coie, J.; Dodge, K.; Kupersmidt, J.B. (1990). Peer group behavior and social status. In S. R. Asher and J. D. Coie (Eds.), Peer rejection in childhood. Cambridge, England: Cambridge University Press, 17-59.

Cooley-Quille, M.R.; Turner, S.M.; Beidel, D.C. (1995). Emotional impact of children's exposure to community violence: A preliminary study. Journal of the American Academy of Child and Adolescence Psychiatry, 34 (10), 1362-1368.

Crespo, F.; Bolaños, M. (2007) Código del preso: acerca de los efectos de la subcultura del prisionero. Capítulo criminológico, 37(2), 52-75.

De Waal, F. (2011). Morality before Religion: Empathy, Fairness and Prosocial Primates. Talk at Stanford University.

Dollar, J.; Doob, L.W.; Miller, N.E.; Mowrer, O.H., \& Sears, R.R. (1939). Frustration and aggression. New Haven, Connecticut: Yale University Press. 
Dorn, L.D.; Susman, E.J.; Ponirakis, A. (2003). Pubertal timing and adolescent adjustment and behavior: conclusions vary by rater. Journal of Youth and Adolescence, 32(3), 157-167.

Fares, N.; Lozano, F.; Cabrera, J. M.; Salas, F., \& Ramírez, J.M. (2010). Justification of interpersonal aggression in Uruguayan children and high school students from different socio-economic strata, measured by $C A M A$ and $R P Q$ questionnaires. Conference Proceedings, Conflict and aggression in a society in transition, Leánfaly, Hungary, 11-12.

Fares, N.; Ramirez, J.M.; Cabrera, J.M.; Lozano, F.; Salas, F. (2011). Justification of physical and verbal aggression in uruguayan children, and adolescents, The Open Psychology Journal, 2011, 4, (Suppl 1-M1) 45-54.

Fehon, D.C.; Grilo, C.M.; Lipschitz, D.S. (2001). Gender differences in violence exposure and violence risk among adolescent inpatients. The Journal of Nervous and Mental Diseases, 189(8), 532-540.

Fontaine, N.; Carbonneau, R.; Barker, E.D.; Vitaro, F.; H'ebert, M.; Côté, S.M.; Nagin, D.S.; Zoccolillo, M., \& Tremblay, R. E. (2008). Girls' hyperactivity and physical aggression during childhood and adjustment problems in early adulthood: A 15-year longitudinal study. Archives of General Psychiatry, 65, 320-328.

Fraçzek, A. (1985). Moral approval of aggressive acts: a Polish-Finish comparative study. Journal of Cross-Cultural Psychology, 16, 41-54.

Fraçzek, A.; Ramirez, J.M., \& Torchalska, B. (1985). Attitudes toward interpersonal aggression. In F. LeMoli (Ed.), Multidisciplinary Approach to Conflict and Appeasement in Animals and Man (pp. 182). Parma: Instituto di Zoologia.

Fromm, E. (1973). The anatomy of human destructiveness. New York: Holt, Rinehart and Winston.

Fujihara, T.; Kohyama, T.; Andreu, J.M.; Ramírez, J.M. (1999) Justification of interpersonal aggression in Japanese, American, and Spanish students. Aggressive Behavior, 25, 185-195.

Gottfredson, M.R.; Hirschi, T. (1990) A general theory of crime. Stanford, CA: Stanford University Press.

Hancock, M.; Tapscott, J.L., \& Hoaken, P.N.S. (2010) Role of executive dysfunction in predicting frequency and severity of violence, Aggressive Behavior, 36, 338-349.

Hasking, P.A.; Scheier, L.M., \& Abadía, A.B. (2011). The three latent classes of adolescent delinquency and the risk factors for membership in each class. Aggressive Behavior, 2011, 37, 19-35.

Lagerspetz K.S., \& Wesmman M. (1980). Moral approval of aggressive acts: a preliminary investigation. Aggressive Behavior, 6, 119-130.

Lagerspetz, K.M.J.; Björkqvist, K.; Björkqvist, H., \& Lundman, H. (1988). Moral approval of aggression and sex role identity in officer trainees, conscientious objectors to military service, and in a female reference group. Aggressive Behavior, 14, 303-313.

Lai-Chu, A.F., Ramirez, J.M., and Poveda, J.M. (in preparation).

Lindeman, M.; Harakka, T.; Keltikangas-Järvinen, L. (1997). Aggression, prosociality and withdrawal as social problem-solving strategies in adolescence. Journal Youth Adolescence, 26, 339-351.

Loeber, R. (1982). The stability of antisocial and delinquent child behavior: A review. Child Development, 53, 1431-1446.

Millana, L.; Halty L., \& Ramírez, J.M. (2009). Justification of different aggression acts in different situations in Spanish young and adolescents. Paper presented at the $28^{\text {th }}$ CICA International Conference. Bodrum (Turkey), 25-28 septiembre.

Musazadeh, Z. (1999). Agresión y su justificación: un estudio comparado de estudiantes iraníes y españoles. Doctoral Dissertation. Universidad Complutense, Madrid.

Osterman, K.; Björkqvist, K.; Lagerspetz, K. M. J.; Kaukiainen, A.; Landau, S.F.; Fraçzek, A.; Caprara, G.V. (1998). Cros-scultural evidence of female indirect aggression. Aggressive Behavior, 24, 1-8.

Penney, S. R.; Lee, Z., \& Moretti, M. M. (2010). Gender differences in risk factors for violence: an examination of the predictive validity of the structured assessment of violence risk in youth. Aggressive Behavior, 36 (6), 390-404.
Ramírez, J.M. (1985a). Attitudes toward aggression in four Spanish regions. In F.L. Moli (Ed.), Multidisciplinary approaches to conflict and appeassement in animals and man (pp. 63). Parma: Instituto di Zoologia.

Ramírez, J.M. (1985b). Hacia una fundamentación biológica de la conducta moral. Biología y Personalidad, Ed. Científico-Médica, Barcelona, 41-45.

Ramírez, J.M. (1986). Comparison of the degree to which aggression is acceptable in four Spanish regions. Paper presented at the 7th Biennial Meeting of ISRA, Chicago.

Ramírez, J.M. (1991). Similarities in attitudes toward interpersonal aggression in Finland, Poland, and Spain. The Journal of Social Psychology, 131, 737-739.

Ramírez, J.M. (1993). Acceptability of aggression in four Spanish regions and a comparison with other European countries. Aggressive Behavior, $19,185-197$

Ramírez, J.M. (2001). Moral approval of aggressive acts by urban students. A cross-national study on four continents. In: Ramírez, J. M. and Richarson, D. S. Cross-Cultural approaches to aggression and reconciliation. Huntington, N.Y.: Nova Science Publishers, Inc. (pp 6171).

Ramírez, J.M. (2007). Justification of Aggression in several Asian and European Countries with different Religious and Cultural Background. International Journal of Behavioral Development, 31(1), Serial No. 51: $9-15$.

Ramírez, J.M. (2010) The Usefulness of Categorizing Aggression according its Function, International Social Science Journal, 200, 65-74.

Ramírez, J.M., \& Andreu, J.M. (2006) Aggression, and some related psychological constructs (anger, hostility, and impulsivity); some comments from a research project. Neuroscience and Biobehavioral Reviews, 30, 276-291.

Ramírez, J.M., \& Fujihara, T. (1997). Taijinteki kougeki koudou ni taisuru taidono hikaku bunkateki kenkyu (in Japanese, with a summary in English). Kwansei Gakuin Daigaku Syakaigakubu Kiyou, 78, 97-103.

Scheier, M. F., Fenigstein, A. \& Buss, A. H. (1974). Self-awareness and physical aggression. Journal of Experimental and Social Psychology, 10: 264-273.

Simourd, L., \& Andrews, D.A. (1994). Correlates of delinquency: A look at gender differences. Forum on Corrections Research, 6(1), 26-31.

South, C. R., \& Wood, J. (2006). Bullying in prisons: The importance of perceived social status, prisonization, and moral disengagement. Aggressive Behavior, 32, 490-501.

Spanish Código Penal y Legislación Complementaria. (2010). Civitas. Trigésima sexta edición. Biblioteca de legislación. Editorial Aranzadi, S. A. Spain.

Stanford, M.S.; Greve, K.W., \& Dickens, T.J. Jr. (1995). Irritability and impulsiveness: relationship to self-reported impulsive aggression. Personality and Individual Differences, 19, 757-760.

Tavecchio, L.W.C.; Stams, G.J.J.M.; Brugman, D., \& Thomeer-Bouwens, M.A.E. (1999). Moral judgement and delinquency in homeless youth. Journal of Moral Education, 28(1), 63-79.

Thompson, L.L.; Riggs, P.D.; Mikulich, S.K., \& Crowley, T.J. (1996). Contribution of ADHD symptoms to substance problems and delinquency in conduct disordered adolescents. Journal of Abnormal Child Psychology, 24, 325-347.

Turner, C.W.; Layton, J. et al. (1975). Naturalistic studies of aggressive behavior: aggressive stimuli, victim visibility, and horn honking. Journal of Personality and Social Psychology, 31(6), 1098-1107.

Valverde, J. (1991). La Cárcel y sus consecuencias. Madrid: Editorial Popular.

Wann, D.; Haynes, G.; McLean, B., \& Pullen, P. (2003). Sport team identification and willingness to consider anonymous acts of hostile aggression. Aggressive Behavior, 29, 406-413.

Wiebush, R. G. (1993). Juvenile intensive supervision: The impact on felony offenders diverted from institutional placement. Crime Delinquency 39, 68-89. 